\title{
Study on the gas emission width of coal seam pressure released by goaf in the deep mine
}

\author{
Siqian $\mathrm{Li}^{1,2, \mathrm{a}^{*}}$, Jianjun $\mathrm{Cao}^{1,2}$ and Yonglei Xie ${ }^{1,2}$ \\ ${ }^{1}$ China Coal Technology and Engineering Group Chongqing Research Institute, Chongqing, China \\ ${ }^{2}$ State Key Laboratory of Gas Disaster Monitoring and Emergency Technology, Chongqing, China
}

\begin{abstract}
The technology of driving along goaf has been widely used in the prevention of high ground stress and coal-gasoutburst in coal mining in our country. In this paper, the 11-2 Coal Seam of zhujixi coal mine is taken as the research object. Based on the test of drilling cuttings and residual gas content at different depths of solid coal at the goaf side and the research on the distribution law, it is concluded that the effective pressure relief drainage belt width at the goaf side of 11-2 Coal Seam after mining is $29 \mathrm{~m}$. Field practice has been carried out in the adjacent working face. The results show that the predicted indexes measured during the coal roadway driving period do not exceed the specified critical value, which verifies the rationality of the width of the discharge zone. The results provide a theoretical support for the reasonable layout of the continuous working face, improve the driving speed of the coal roadway, reduce the cost of gas control, improve the economic benefits of the mine, and ensure the safety production of the mine.
\end{abstract}

\section{Introduction}

With the increase of mining depth, the gas pressure and gas content in coal seam continue to increase and the level of ground stress in mining area increases significantly. This usually causes more and more serious coal-gas outbursts and the deep in-situ stress-dominated outburst disasters also increase significantly ${ }^{[1]}$. Hence, the realizing of both the coal seam stress releasing and the gas pressure releasing at coal and gas outburst seam in deep mines is the key point to ensure safe and efficient production of coal mines. Mining practices at home and abroad have shown that mining at the working face can destroy the stress balance of the surrounding rocks and lead to the stress concentration near the mining space, which further leads to the plastic failure of coal and rock mass. And during this process, the stress concentration gradually evolves to the interior of coal and rock, which results in the pressure releasing and structural failure of coal and rock in a certain range near the mining space and accelerates the coal permeability and gas emission in this $\operatorname{area}^{[2,3]}$. After a period of mining at the working face, a pressure releasing protection belt with a certain width along the coal seam layer would be formed. And the regional outburst prevention measures within the pressure releasing protection belt will be effective $e^{[4-6]}$. Hence, studying and determining the pressure releasing width in the goaf in the coal and gas outburst seam is of great significance to the implementation of outburst prevention measures, the excavation layout in the working face area and the improvement of mining speed.

For this reason, taking the 11-2 coal seam of Zhujixi
Mine as the research object, the coal cuttings in different depths in the goaf side, the residual gas content and the pressure distribution of the gas were investigated in the mined area of the 11501 working face and the reasonable width of gas emission with pressure releasing in the11-2 coal seam was determined through the verification of practical mining process, which provides a basis for the reasonable setting of the coal pillars in the continuous working face in the 11-2 coal seam of the mine and the formulation of comprehensive gas control measures.

\section{Engineering background}

The average thickness of coal seam is $1.55 \mathrm{~m}$ and the average dip angle is $5^{\circ}$. It is a near horizontal coal seam with buried depth of $960 \sim 1080 \mathrm{~m}$, maximum gas content of $8.39 \mathrm{~m}^{3} / \mathrm{t}$, maximum gas pressure of $0.45 \mathrm{MPa}$, initial gas emission velocity of $6 \sim 9 \mathrm{mmHg}$ and firmness coefficient of $0.64 \sim 0.98$. The roof and floor are composed of mudstone and siltstone. The roadway is of rectangular section and supported by bolt and mesh. The working face adopts one-time full height backward mining technology, and the roof is managed by full caving method. $7.5 \mathrm{~m}$ coal pillar shall be reserved with adjacent working face.

\section{Coal seam natural pressure relief discharge theory}

Coal mining operations disrupted the stress balance of the coal seam, resulting in coal body rheology and gas flow. A stress concentration is formed near the interface of the mining space. When the stress concentration reaches the

\footnotetext{
a*siqian_licqmk@163.com
} 
ultimate strength of the coal body, the coal body undergoes yield deformation and failure, the concentrated stress transfers to the deep part and the deformation and failure develop to the deep part, forming a pressure relief zone, a stress concentration zone and original rock stress district $^{[7]}$. The lateral stress distribution in the goaf is shown in Fig. 1.

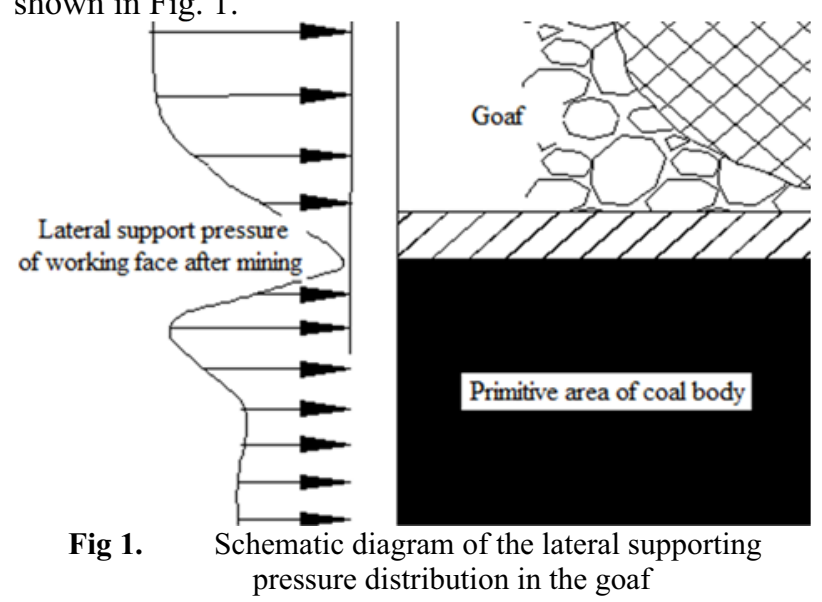

The coal seam in the pressure relief zone develops cracks and increases air permeability. Due to the gas pressure gradient between the coal body and the coal wall, the gas in the coal body in the pressure relief zone gushes out to the roadway along the coal body cracks and pores, and the gas gushes out strength as the exposure time of the coal wall increases, a large amount of gas escapes through the cracks and the gas content decreases. Therefore, the pressure relief zone is often considered as a nonprotruding danger zone.

\section{Investigation indicators and determination of emission zone width}

\subsection{Determination of inspection indicators}

Research shows that the initial velocity of gas emission from boreholes mainly reflects the size of coal seam gas and permeability; the amount of drilling cuttings mainly reflects the physical properties of coal and the size of the in-situ stress; the index of drilling cuttings gas desorption mainly reflects the speed of coal seam desorption; gas content and the pressure mainly reflects the outburst danger degree of the coal seam. Therefore, according to the attributes of coal seam outburst or dynamic disaster, select indicators with higher predictive sensitivity to investigate the pressure relief width, combined with the comprehensive analysis of the residual gas content inspection to determine the pressure relief discharge width.

According to the measured gas parameters and mining practice, the 11-2 Coal seam is a stress dominated outburst coal seam, and the drilling cuttings quantity index has a high sensitivity to predict the risk of coal seam outburst, while the initial gas emission velocity and drilling cuttings gas desorption index have a relatively poor sensitivity. Therefore, the indexes for the width of natural pressure relief drainage zone are the amount of drilling cuttings and the content of residual gas.

\subsection{Design of investigate drilling}

According to the theoretical analysis, the width of the pressure relief zone on both sides of the goaf is much larger than that on both sides of the solid coal roadway, that is, the pressure relief zone formed by the driving roadway is very limited relative to the goaf. According to the mining situation of No.5 mining area in No.11-2 coal seam of the mine, a group of investigation boreholes are arranged in the tail roadway of 11502 working face. The spacing of boreholes is $10 \mathrm{~m}$ and the depth of boreholes is $20 \mathrm{M}$ (the distance between the final hole and the goaf is $33 \mathrm{~m})$. A total of 6 boreholes are designed. The drilling layout is shown in Fig. 2.

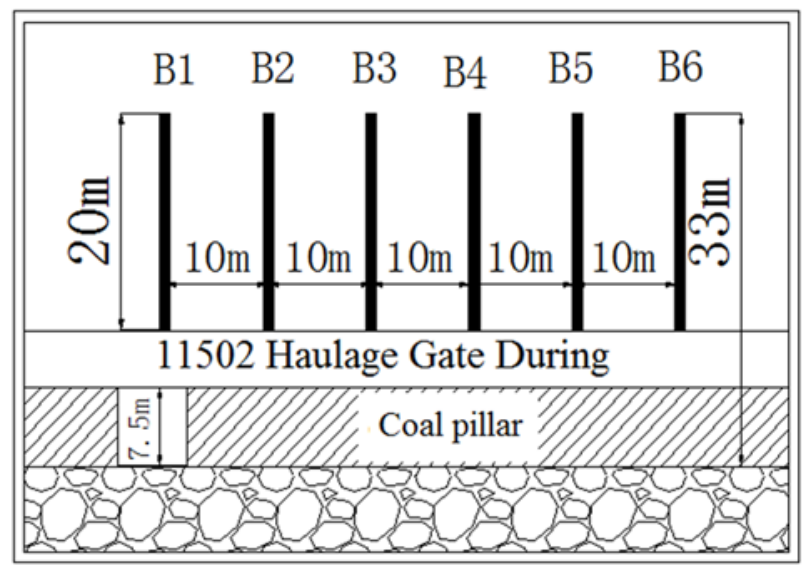

Fig 2. Diagram of drilling arrangement

\subsection{Analysis of investigation result}

\subsubsection{Investigation of drillings volume}

The amount of drilling cuttings is different in different stress distribution areas of goaf side. The width of the pressure relief zone around the mining face is determined according to the variation law of the amount of drilling cuttings in different depths of the coal body. When the abnormal dynamic phenomenon occurs in a certain depth of the borehole or the amount of drilling cuttings increases suddenly compared with the previous depth, it indicates that the depth has entered the stress concentration area beyond the mining pressure relief width, and the drilling depth at the mutation point is determined as the width of the pressure relief zone.

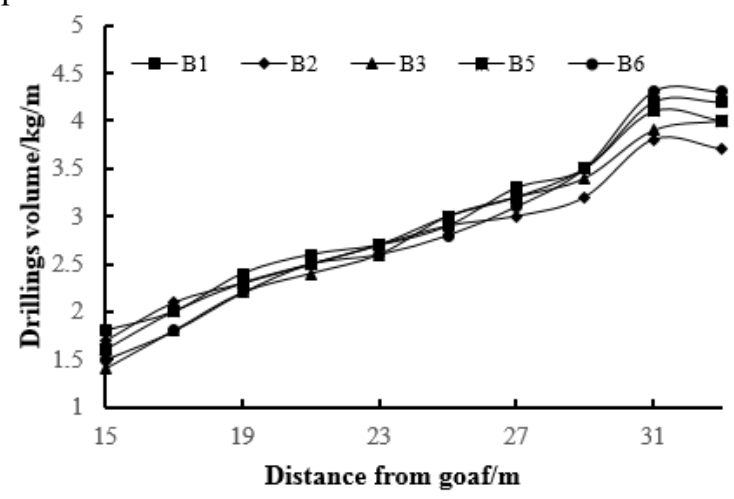

Fig 3. Variation curve of drillings volume with different distances from roadway side 
The cuttings quantity is tested every $2 \mathrm{~m}$ from the $2 \mathrm{nd}$. The relationship between cuttings quantity and hole depth is shown in Fig. 3.

According to figure 3 , the drilling cuttings increase linearly with the increase of drilling depth. When the drilling depth reaches $29 \sim 31 \mathrm{~m}$, the drilling cuttings increase sharply and reach the maximum value. After the drilling depth is $31 \mathrm{~m}$, the drilling cuttings amount has a downward trend and basically keeps stable. During the drilling construction, there is no abnormal dynamic phenomenon such as drilling clamping. Therefore, 29$31 \mathrm{~m}$ outside the goaf is determined to be stress concentration area and the relief width is $29 \mathrm{~m}$.

\subsubsection{Investigation of residual gas content}

On the basis of determining the width of the pressure relief zone in the goaf, by testing the residual gas content in the width of the pressure relief zone and analyzing its decline law, combined with the regional outburst risk prediction index, the range of the residual gas content less than the critical value of the regional outburst risk index is determined as the width of the side drainage zone in the goaf.

From $21 \mathrm{~m}$ away from the goaf, coal samples are taken every $3 \mathrm{~m}$ to test the residual gas content. The relationship between the residual gas content and the hole depth is shown in Figure 4.

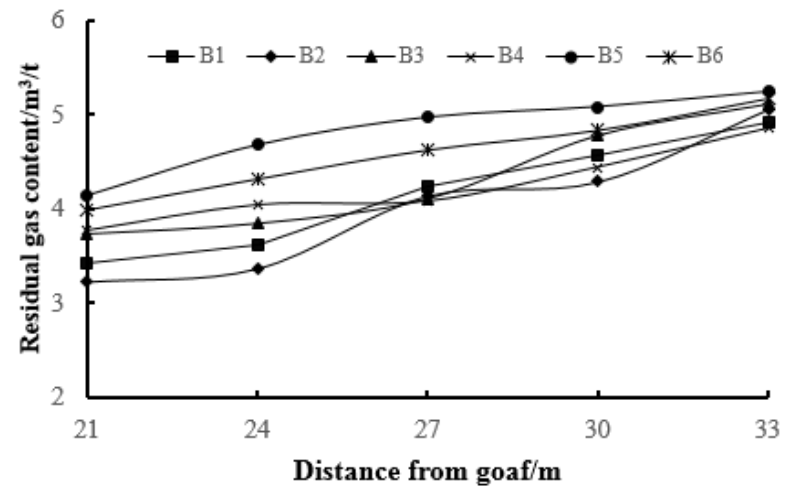

Fig 4. Curve of residual gas content with different distance from roadway side

According to the analysis in Figure 4, the residual gas content of 11-2 Coal Seam measured at different distances from the goaf is $3.43 \sim 5.24 \mathrm{~m}^{3} / \mathrm{t}$, and the residual gas content gradually increases with the increase of the distance from the coal wall. The original gas content of 112 Coal seam is $7.17 \mathrm{~m}^{3} / \mathrm{t}$ measured in advance during the driving of 11502 transport crossheading, and the reduction rate of residual gas content in different depths is $26.9 \%$ $55.5 \%$ by calculation. According to the variation trend of residual gas content decline rate at different distances from solid coal of 11-2 coal seam adjacent to the coal wall of goaf, the relationship curve between the decline rate $\mathrm{V}$ and the distance $\mathrm{L}$ from goaf is drawn based on the minimum decline rate of residual gas content at each interval, as shown in Fig. 5.

Based on the analysis of Fig. 5, the relationship between the reduction rate of residual gas content in different drilling depths on the side of goaf is as follows:

$$
V=0.8473 \mathrm{e}^{-0.036 L} \quad(21 \mathrm{~m} \leq L \leq 33 \mathrm{~m})
$$

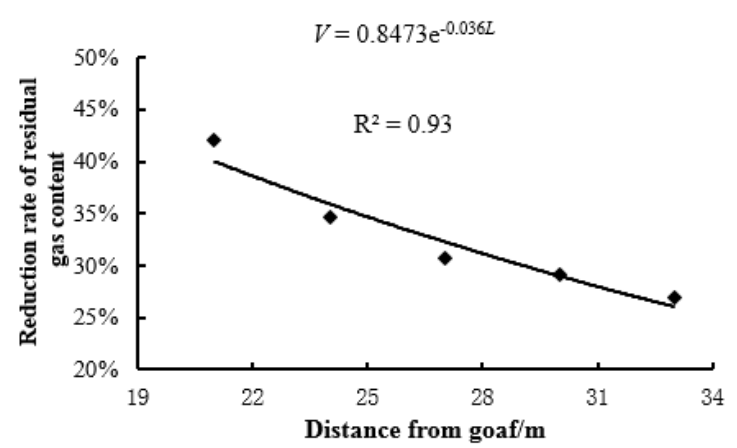

Fig 5. Reduction rate curve of residual gas content at different hole depths

According to the fitting relationship of the decline rate of residual gas content, the decline rate of residual gas content is $29.8 \%$ at the pressure relief width of $29 \mathrm{~m}$. On the one hand, according to the measured results in the experimental area, the maximum residual gas content within the pressure relief width of $29 \mathrm{~m}$ in the goaf is less than $5.08 \mathrm{~m}^{3} / \mathrm{t}$, and the gas drainage effect in the pressure relief area is better; On the other hand, according to the maximum gas content of 11-2 Coal Seam in the test area is $8.38 \mathrm{~m} 3 / \mathrm{t}$, combined with the fitting relationship of the decline rate of the residual gas content, the residual gas content within the range of $29 \mathrm{~m}$ of the pressure relief width of the goaf can be reduced to less than $5.88 \mathrm{~m}^{3} / \mathrm{t}$, which is less than the verification index of $7.23 \mathrm{~m}^{3} / \mathrm{t}$ of the residual gas content determined in this scheme.

In summary, the width of the pressure relief drainage zone at the goaf side of the test area is $29 \mathrm{~m}$.

\section{Driving verification of the effectiveness of the gas emission width}

According to the roadway layout in the 11-2 coal seam, the gateroad of 11401 working face, which is adjacent to 11501 working face, is driven along the goaf. The coal pillar width between the gateroad and the goaf of 11501 working face is $7.5 \mathrm{~m}$ and the roadway is arranged within the gas emission width with pressure releasing of 11501 working face. In order to verify the rationality of the determination of the gas emission width, the amount of cuttings and the drill cutting desorption index $K_{1}$ were used for cyclic prediction during the gateroad driving process of 11401 working face. The predicted borehole depth is $10 \mathrm{~m}$, the hole diameter is $42 \mathrm{~mm}$, and the two sides of the tunnel are controlled for 2 4m. Layout and location of circular prediction boreholes in heading face of coal roadway in shown in Fig. 6.The maximum prediction index distribution during the driving process is shown in shown in Fig. 7. 


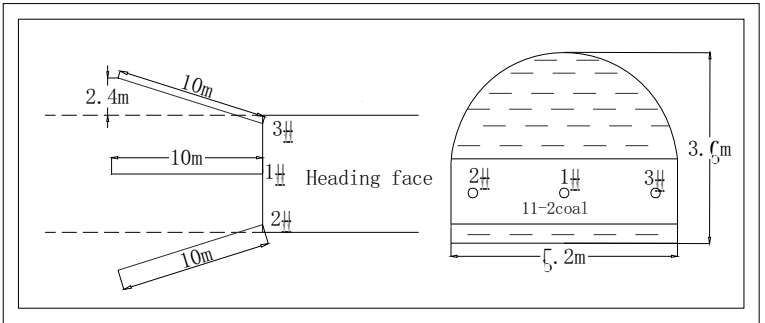

Fig 6. Layout and location of circular prediction boreholes in heading face of coal roadway

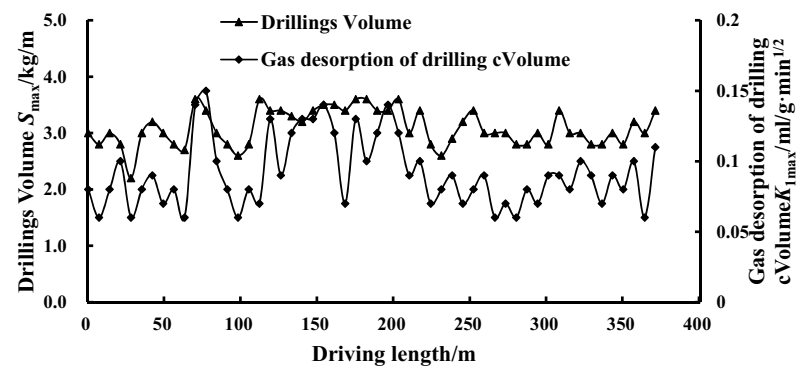

Fig 7. Relationship between cycle prediction index of heading face and roadway footage

According to the analysis in Fig. 6, during the driving of 11401 transport crossheading, the drilling cuttings quantity $\mathrm{s}$ is generally $2.8 \sim 3.4 \mathrm{~kg} / \mathrm{m}$, and the drilling cuttings desorption index $K_{1}$ is generally $0.06 \sim 0.09 \mathrm{ml} / \mathrm{g} \cdot \mathrm{min}^{1 / 2}$. The drilling cuttings quantity and drilling cuttings desorption index do not exceed the standard and have abnormal dynamic phenomenon; The gas concentration is $0.06 \% \sim 0.1 \%$ during coal roadway driving, the maximum absolute gas emission is $0.2 \mathrm{~m}^{3} / \mathrm{min}$, and there is no abnormal gas emission. In the case of no regional outburst prevention measures taken in 11401 transport crossheading, the safe driving of crossheading is realized, which shows that the pressure relief effect of goaf side pressure relief drainage belt is remarkable, and verifies the rationality of the width of goaf side pressure relief drainage belt in 11-2 Coal seam

\section{Conclusion}

(1) Through the analysis on the change regularities of the residual gas in the goaf of 11501 working face, the relationship between the decrease rate of residual gas $\mathrm{V}$ and the distance from the goaf $\mathrm{L}$ can be obtained, $\mathrm{V}=0.8473 \mathrm{e}^{-0.036 L} \quad(21 \mathrm{~m} \leq L \leq 33 \mathrm{~m})$. And the natural gas emission width with pressure releasing in the goaf of the 11-2 coal seam can be determined as $29 \mathrm{~m}$ based on the analysis on the change regularities of the amount of cuttings and the residual gas content.

(2) Neither the amount of drillings volume nor the desorption index of drill cuttings has exceeded the standard during driving process along the goaf. And there was no gas abnormal emission happened. The safe roadway driving along the goaf further verified the validity of the natural gas emission width with pressure releasing.

(3) The research results have effectively guided the roadway layout and the safe driving of the 11-2 coal seam connecting face. And it can provide an evidence for the design of the 11-2 coal seam face and comprehensive harness of gas under similar conditions.

\section{References}

1. Wang Jinbao. Investigation on effective protection range of gob-side drifting roadway in outburst coal seam [J]. Coal mine safety, 2018,49 (06): 5-7.

2. $\mathrm{Xu}$ Kun, Li Peng, Ni Xing. Investigation and Research on Effective Range of Pressure Relief in Goaf Area after No.9 Coal Seam Mining in Gaoshan Coal Mine [J]. Inner Mongolia Coal Economy, 2020 (07): 33-34.

3. Sun Shijin, Zhu Zhen, Xiang Changzheng, Meng Fance, Feng Liangqing. Study on pressure relief zone and gas emission law of gob side mining in Dazhong coal mine $[\mathrm{J}]$. Energy technology and management, 2012 (03): 76-77.

4. Xu Zunyu. Study on lateral pressure relief gas drainage width of goaf in 1\# Coal Seam of Xinji No.2 coal mine [J]. Coal mine safety, 2018,49 (02): 159162.

5. Sun Rui. Method for determining width of gas pressure relief drainage zone based on finite flow field [J]. Journal of Shenyang University of technology, 2018,37 (03): 80-85.

6. Sun Zhiguo. Measurement and numerical simulation analysis of parameters related to width of gas drainage zone $[J]$. Shanxi chemical industry, 2019,39 (01): 33-35 + 46 .

7. Zhang Mingjie, Fu Shuai, Tan Zhihong. Determination of outburst prevention range of goaf pressure relief zone in single low permeability coal seam [J]. Coal science and technology, 2014,42 (08): 25-28. 